\title{
Evaluation of Serum Creatine Kinase and Urinary Myoglobin as Markers in Detecting Development of Acute Renal Failure in Severely Injured Trauma Patients
}

\author{
Arulselvi Subramanian,, Deepti Sukheeja, ${ }^{1}$ Vivek Trikha, ${ }^{2}$ Arbind Kumar Pandey, \\ Venencia Albert, ${ }^{1}$ and Ravindra Mohan Pandey ${ }^{3}$ \\ ${ }^{1}$ Department of Laboratory Medicine, Jai Prakash Narayan Apex Trauma Centre (JPNATC), AIIMS, New Delhi 110022, India \\ ${ }^{2}$ Department of Orthopaedics, Jai Prakash Narayan Apex Trauma Centre (JPNATC), AIIMS, New Delhi 110022, India \\ ${ }^{3}$ Department of Biostatistics, AIIMS, New Delhi 110022, India
}

Correspondence should be addressed to Arulselvi Subramanian; arulselvi.jpnatc@gmail.com

Received 1 July 2013; Accepted 4 August 2013

Academic Editors: A. K. Attri and A. Banerjee

Copyright (C) 2013 Arulselvi Subramanian et al. This is an open access article distributed under the Creative Commons Attribution License, which permits unrestricted use, distribution, and reproduction in any medium, provided the original work is properly cited.

\begin{abstract}
Background. Presence of myoglobinuria, particularly in the early phases of renal failure, and elevation of creatinine kinase are seen to correlate with the development of acute renal failure. Aim. To evaluate the efficiency of serum creatine kinase (CK) and urine myoglobin in assessing development of renal failure. Materials and Method. We prospectively studied trauma patients over a period of 3 months. Samples of 107 patients were routinely analyzed on the 1st, 3rd, and 5th days post trauma, for myoglobinuria and serum CK concentration. Results. 107 patients with median age 28 (4-83) yrs were studied, of which $83.2 \%$ were males. 56\% had head injury, and $17.1 \%$ had high injury severity (ISS > 24). Incidence of renal failure was $9.3 \%$. Myoglobinuria was present in 57 patients on admission, 33 on 3rd day and 22 on the 5th day. The association of myoglobinuria with renal failure was statistically insignificant. The cutoff values of serum CK on the 1 st, $3 \mathrm{rd}$, and 5 th days were $\geq 1320 \mathrm{IU} / \mathrm{L}, \geq 1146 \mathrm{IU} / \mathrm{L}$, and $\geq 1754 \mathrm{IU} / \mathrm{L}$, respectively. Mortality rate was 24 (22.4\%), of which 6 had renal failure. Conclusion. Myoglobin is clinically insignificant in the detection of renal failure; serum CK is a sensitive predicting marker for the progression of renal failure following traumatic injury.
\end{abstract}

\section{Introduction}

Urine myoglobin and serum creatinine kinase (CK) continue to be used as biomarker of rhabdomyolysis, particularly to assesses risk of developing renal failure. Rhabdomyolysis was first described in the victims of crush injury in Sicilian earthquake in Messina in 1908 and those in World War I. Myoglobin is filtered by the kidney and appears in the urine when the plasma concentration exceeds $1.5 \mathrm{mg} / \mathrm{dL}$. Rhabdomyolysis with renal failure is one of the most serious complications of traumatic patients. We sought to determine the predictive validity of urine myoglobin renal failure in posttraumatic patients. Road traffic accident (RTA)/motor vehicle accident (MVA), crush injury, surgery, and any natural disaster trauma are associated with the release of large amount of myoglobin and serum creatinine kinase
(CK) into circulation [1]. At high serum concentrations, myoglobin precipitates in the kidney, both through pigment glomerulopathy and obstructive tubulopathy resulting in renal failure.

Creatine phosphokinase (CK) is an enzyme, released into the blood stream on muscle cell disintegration. It exists in three isomeric forms: CK-MM present in muscles, CK-MB present in heart, and CK-BB present in kidneys and brain. Normal range of serum CK in males is $39-308 \mathrm{IU} / \mathrm{L}$ and in females is $26-292 \mathrm{IU} / \mathrm{L}$. CK rises in rhabdomyolysis within 12 hours of the onset of muscle injury, peaks in 1-3 days, and declines 3-5 days after the cessation of muscle injury; serum half-life is approximately 36 hours. Failure of CK levels to decrease suggests ongoing muscle injury, and the peak CK level may be predictive of the development of renal failure. The development of renal failure in the presence 
of rhabdomyolysis with significantly elevated CK is well described [2-4].

Myoglobinuria appears as reddish brown, dark colored urine, when its concentration is very high, that is, $>300,000 \mu \mathrm{g} / \mathrm{L}$, but in less extreme case, myoglobinuria is not grossly visible [5-7]. Urine dipstick test for blood that has positive findings in the absence of red blood cells suggests myoglobinuria. We therein designed the following prospective investigation for urine rapid test specific for myoglobin and serum $\mathrm{CK}$ to determine their role in the diagnosis of renal failure.

\section{Materials and Methods}

2.1. Study Subjects. The study was conducted over a period of three months, that is, from February to March 2011, in traumatic patients admitted to the Emergency Department of Level I Tertiary Care Trauma Center, on road traffic accident, motor vehicle accident, blunt injury under influence of alcohol, or morning walk people. Routine samples which include male and female patients and all age groups of posttraumatic patients were collected. Patients with drug abuse and on anti-psychotics were excluded from the study. The ethical clearance was obtained from the review committee for the purpose of study.

2.2. Data Collection. Data compilation included age, sex, severity of injury, mode of injury, clinical and laboratory investigations on admission, and followup (3rd and 5th days) records. Patients baseline parameters, age, gender, organ failure, sepsis, type of injury, injury severity score, Glasgow coma scale, systolic arterial blood pressure and outcome during hospitalization, were recorded in excel sheet. All of the subjects consecutive 1st, 3rd, and 5th days routine blood examination, such as complete blood cell count, prothrombin time (PT), activated partial thromboplastin time (aPTTs) and biochemistry test (including Renal function test, Liver function test, and electrolytes) were done. In addition, serum CK was measured and presence or absence of urine myoglobin was seen.

For detection of myoglobinuria, urine samples were centrifuged at $3000 \mathrm{rpm}$ for 10 minutes and urine was passed through a $50 \mathrm{kDa}$ cutoff filter. Myoglobin (molecular weight $17.8 \mathrm{kDa}$ ) asses the filter whereas the larger hemoglobin (molecular weight $68 \mathrm{kDa}$ ) is retained on filter. The filtrate was then tested for myoglobin with hemoglobin dipstick. Positive results were reported as myoglobin detected. The absence of red cells on microscopy confirmed that the discolored urine is caused by myoglobin.

Microscopic examination was done to check for the presence of RBCs, casts, and other types of cells, if present. Serum CK concentration was determined with an immunoturbidimetric assay on Hitachi Roche 902 Automatic Analyzer (Hitachi Medical, Tokyo, Japan).

Patients with hypotension, arrhythmia and on vasopressors were considered to have cardiovascular dysfunction. Patients with the aspartate transaminase (AST) level $>80 \mathrm{IU} / \mathrm{L}$ or serum bilirubin level $>3 \mathrm{mg} \%$ were considered to have hepatic dysfunction. Central nervous system dysfunction was defined as patients with severe head injury, that is, GCS $<8$. Pulmonary dysfunction was defined as the presence of bilateral lung infiltrate or acute respiratory distress syndrome (ARDS) or central venous pressure $<18 \mathrm{~mm} \mathrm{Hg}$ and on mechanical ventilation. Patients with coagulopathy (PT/or aPTT $\geq 1.5 \times$ times the control) were considered to have hematology dysfunction. ARF for the purpose of our study was defined as serum creatinine levels $>2 \mathrm{mg} / \mathrm{dL}[8,9]$.

2.3. Statistical Analysis. Data analysis was performed using SPSS16.0 statistical software. Serum CK levels on 1st, 3rd, and 5 th days for the study group were summarized as median \pm $\mathrm{SD}$, and myoglobin results were dichotomized on the basis of test positivity and summarized as frequency (\%). Categorical variables were compared via chi-square $\left(\chi^{2}\right)$ analyses and continuous variables were compared with $t$-test. Patients were categorized into groups on the basis of occurrence of any organ system failure; comparison for the difference in levels of CK and myoglobin results was done using $t$ test and chi-square analysis between the groups. $P$ values $<0.05$ were considered significant. Receiver operating curve analysis (ROC) was done to obtain the sensitivity, specificity, and cutoff values for serum CK to identify patients at a risk for developing renal failure after trauma.

\section{Results}

There were 107 patients with serum CK and urine myoglobin recorded on the 1st, $3 \mathrm{rd}$, and 5 th days of admission. The median age of the study group was 28 (4-83) years. Eightynine $(83.2 \%)$ of them were men and $18(16.8 \%)$ women. Table 1 depicts the baseline characteristics of the study group.

The major site of trauma involved was head (56\%) (Figure 1). The incidence of renal failure was about 9.3\% (10 out of 107 severely injured patients). Urine myoglobin was present in 57 patients on the 1st day, 33 on the 3rd day, and 22 on the 5th day (Figure 2).

The study group was categorized into patients who developed renal failure and those who did not, and on admission laboratory values were compared between the two. There was a significant difference in the levels of aPTT $(P=0.006)$, serum potassium $(P=0.04)$, blood urea $(P=0.05)$, and serum CK $(P<0.001)$ on day 1 . On day 3 , values of hemoglobin were higher in those who did not have renal failure but significantly lower in those who developed renal failure $(P=0.01)$. The same is with hematocrit $(P=0.01)$, prothrombin time $(P \leq 0.001)$, serum sodium $(P \leq 0.001)$, blood urea $(P=0.01)$, CK $(P=0.006)$, and creatinine $(P=$ $0.03)$. On day 5 , levels of hematocrit were higher in patients without renal failure $(P=0.08)$ and levels of serum CK were lower compared to the other group $(P=0.03)$ (Table 2).

\subsection{Comparison of Myoglobin with Incidence of Renal Failure.} On the 1st day, 57 patients were found positive for urine myoglobin, out of which $10 \%$ developed renal failure $(P=$ 0.68 ). On the 3 rd day, 33 were positive for urine myoglobin out of which $7 \%$ developed renal failure $(P=0.28)$. On 
TABLE 1: Baseline characteristics of the study group.

\begin{tabular}{|c|c|}
\hline Parameter & Frequency \\
\hline Age $^{*}$ & $33 \pm 16$ \\
\hline \multicolumn{2}{|l|}{ Sex } \\
\hline Men & $89(83.2)$ \\
\hline Women & $18(16.8)$ \\
\hline \multicolumn{2}{|l|}{ Organ failure } \\
\hline Yes & $58(54.2)$ \\
\hline No & $49(45.8)$ \\
\hline \multicolumn{2}{|l|}{ Cardiac failure } \\
\hline Yes & $9(8.4)$ \\
\hline No & $98(91.6)$ \\
\hline \multicolumn{2}{|l|}{ Hepatic failure } \\
\hline Yes & $32(29.9)$ \\
\hline No & $75(70.1)$ \\
\hline \multicolumn{2}{|l|}{ Renal failure } \\
\hline Yes & $10(9.3)$ \\
\hline No & $97(90.6)$ \\
\hline Permanent & $3(30)$ \\
\hline Transient & $7(70)$ \\
\hline \multicolumn{2}{|l|}{ Pulmonary failure } \\
\hline Yes & $23(21.5)$ \\
\hline No & $84(78.5)$ \\
\hline \multicolumn{2}{|l|}{ Sepsis } \\
\hline Yes & $4(3.74)$ \\
\hline No & $103(96.3)$ \\
\hline \multicolumn{2}{|l|}{ Type of injury } \\
\hline \multicolumn{2}{|l|}{ Head injury } \\
\hline Severe & $38(35.5)$ \\
\hline Moderate & $12(11.2)$ \\
\hline Minor & $10(9.3)$ \\
\hline Blunt abdomen trauma & $12(11.2)$ \\
\hline Cervical spine injury & $3(2.8)$ \\
\hline Fracture & $6(5.6)$ \\
\hline Faciomaxillary injury & $5(4.6)$ \\
\hline Soft tissue & $3(2.8)$ \\
\hline Electrocuted, suicide, fall, and gunshot & $18(16.8)$ \\
\hline \multicolumn{2}{|l|}{ Injury severity score } \\
\hline$\leq 24$ & $89(83.1)$ \\
\hline$>24$ & $18(17.1)$ \\
\hline \multicolumn{2}{|l|}{ Glasgow coma score } \\
\hline 14-15, mild & $43(40.2)$ \\
\hline $8-13$, moderate & $28(26.2)$ \\
\hline $1-7$, severe & $36(33.6)$ \\
\hline \multicolumn{2}{|l|}{ Systolic arterial blood pressure $\mathrm{mm}$ of $\mathrm{Hg}$} \\
\hline Hypotension, $<90$ & $8(7.5)$ \\
\hline Normal, 90-120 & $60(56.1)$ \\
\hline Hypertension, $>120$ & $39(36.4)$ \\
\hline \multicolumn{2}{|l|}{ Coagulopathy } \\
\hline Yes & $21(19.6)$ \\
\hline No & $86(80.3)$ \\
\hline
\end{tabular}

TABle 1: Continued.

\begin{tabular}{ll}
\hline Parameter & Frequency \\
\hline Immediate hospital outcome & \\
Dead & $24(22.4)$ \\
Discharged & $83(77.6)$ \\
\hline Data expressed as percentage or ${ }^{*}$ mean \pm SD. &
\end{tabular}

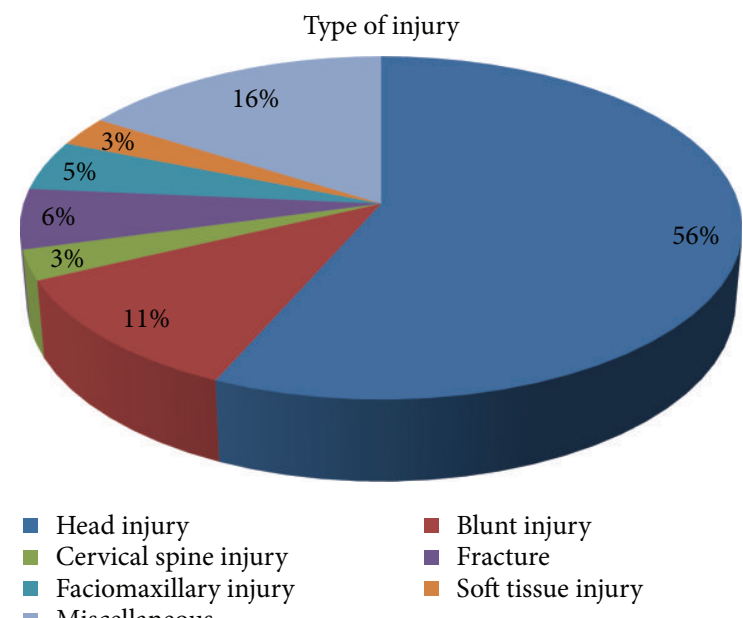

FIGURE 1: Various sites of trauma of the study group.

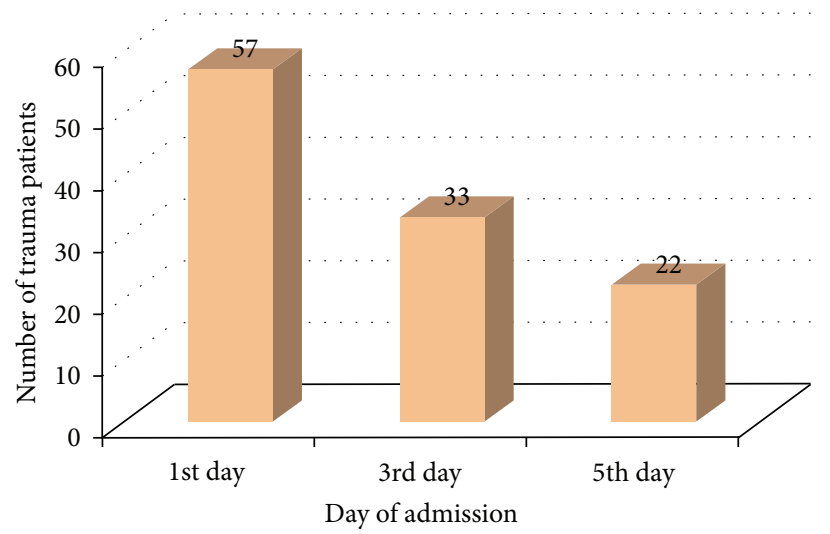

FIGURE 2: Myoglobin positivity in urine on admission, day 3 and day 5 of followup.

the 5th day, 22 were positive for urine myoglobin, out of which $23 \%$ developed renal failure $(P=0.25)$. However, the association of urine myoglobin with renal failure was not observed to be of any statistical significance (Figure 2).

3.1.1. Correlation of Renal Failure with Mortality. The overall mortality rate of the study was $22.4 \%$ (24 out of 107) and mortality rate due to renal failure was $60 \%$; that is, 4 patients of the renal failure group survived throughout their hospital stay $P<0.008$ (Figure 3 ).

3.1.2. Correlations of Serum CK and Creatinine. The cutoff value of serum CK on the 1st day was around $\geq 1320$ IU/L by 
TABLE 2: Comparison of laboratory variables between patients with and without renal failure using $t$ - test.

\begin{tabular}{|c|c|c|c|}
\hline Parameters & No renal failure $N=97$ & Renal failure $N=10$ & $P$-value \\
\hline \multicolumn{4}{|l|}{ Hemoglobin } \\
\hline Day 1 & $10.8 \pm 2.5$ & $10.3 \pm 2.4$ & 0.4 \\
\hline Day 3 & $9.8 \pm 2.3$ & $7.7 \pm 1.5$ & 0.01 \\
\hline Day 5 & $9.8 \pm 2.1$ & $8.4 \pm 1.04$ & 0.08 \\
\hline \multicolumn{4}{|l|}{ Hematocrit } \\
\hline Day 1 & $33.9 \pm 11.4$ & $32.13 \pm 7.5$ & 0.6 \\
\hline Day 3 & $30.51 \pm 6.75$ & $25.7 \pm 7.2$ & 0.04 \\
\hline Day 5 & $31.8 \pm 8.8$ & $25.17 \pm 3.7$ & 0.05 \\
\hline \multicolumn{4}{|l|}{ TLC } \\
\hline Day 1 & $12050(3000-38800)$ & $9650(6800-15500)$ & 0.1 \\
\hline Day 3 & $9800(1440-30600)$ & $7500(5200-23900)$ & 0.4 \\
\hline Day 5 & $9600(2500-25900)$ & $8900(4500-21900)$ & 0.8 \\
\hline \multicolumn{4}{|c|}{ Platelet counts } \\
\hline Day 1 & $159(40-900)$ & $157(80-270)$ & 0.9 \\
\hline Day 3 & $140(34-830)$ & $130(40-180)$ & 0.8 \\
\hline Day 5 & $152.5(58-960)$ & $110(40-206)$ & 0.1 \\
\hline \multicolumn{4}{|l|}{ PT } \\
\hline Day 1 & $16.2(12.7-37.9)$ & $18.25(15.4-19.1)$ & 0.7 \\
\hline Day 3 & $15.75(13.3-24.8)$ & $17.3(15-40.1)$ & $<0.001$ \\
\hline Day 5 & $15.25(11.9-33.3)$ & $17.4(15.6-20.9)$ & 0.6 \\
\hline \multicolumn{4}{|l|}{ APTT } \\
\hline Day 1 & $28.65(20-55)$ & $31(21.6-66.1)$ & 0.006 \\
\hline Day 3 & $28.4(18.2-81.8)$ & $31(26.9-59.4)$ & 0.2 \\
\hline Day 5 & $30.4(18-136.7)$ & $27.85(24.9-37.7)$ & 0.6 \\
\hline \multicolumn{4}{|l|}{$\mathrm{Na}$} \\
\hline Day 1 & $140.5 \pm 5.2$ & $141.8 \pm 10.7$ & 0.50 \\
\hline Day 3 & $140.9 \pm 8.45$ & $151.7 \pm 12.7$ & $<0.001$ \\
\hline Day 5 & $140.0 \pm 7.8$ & $143.3 \pm 5.3$ & 0.28 \\
\hline \multicolumn{4}{|l|}{ K } \\
\hline Day 1 & $3.8 \pm 0.7$ & $4.3 \pm 1.1$ & 0.04 \\
\hline Day 3 & $3.5 \pm 0.8$ & $3.9 \pm 0.8$ & 0.21 \\
\hline Day 5 & $3.4 \pm 0.7$ & $3.5 \pm 0.9$ & 0.7 \\
\hline \multicolumn{4}{|l|}{$\mathrm{Ca}$} \\
\hline Day 1 & $8.4 \pm 1.1$ & $7.8 \pm 1.6$ & 0.1 \\
\hline Day 3 & $7.8 \pm 1.1$ & $7.7 \pm 1.1$ & 0.7 \\
\hline Day 5 & $7.6 \pm 1.3$ & $7.9 \pm 0.7$ & 0.5 \\
\hline \multicolumn{4}{|l|}{ Urea } \\
\hline Day 1 & $24(7-76)$ & $58(13-240)$ & 0.05 \\
\hline Day 3 & $26(8-66)$ & $64(30-227)$ & 0.01 \\
\hline Day 5 & $29(8-79)$ & $83(33-170)$ & 0.07 \\
\hline \multicolumn{4}{|l|}{ Creatinine } \\
\hline Day 1 & $0.7(0.3-2.3)$ & $0.7(0.2-10.6)$ & 0.5 \\
\hline Day 3 & $0.7(0.3-2.8)$ & $0.8(0.2-8.1)$ & 0.03 \\
\hline Day 5 & $0.5(0.3-2.1)$ & $0.6(0.1-5.30)$ & 0.03 \\
\hline \multicolumn{4}{|l|}{$\mathrm{CK}$} \\
\hline Day 1 & $287(4-4730)$ & $620(4-16923)$ & $<0.001$ \\
\hline Day 3 & $636.5(33-5738)$ & $1360(15-14345)$ & 0.006 \\
\hline Day 5 & $416(7-2540)$ & $1280.5(1-8222)$ & 0.03 \\
\hline
\end{tabular}




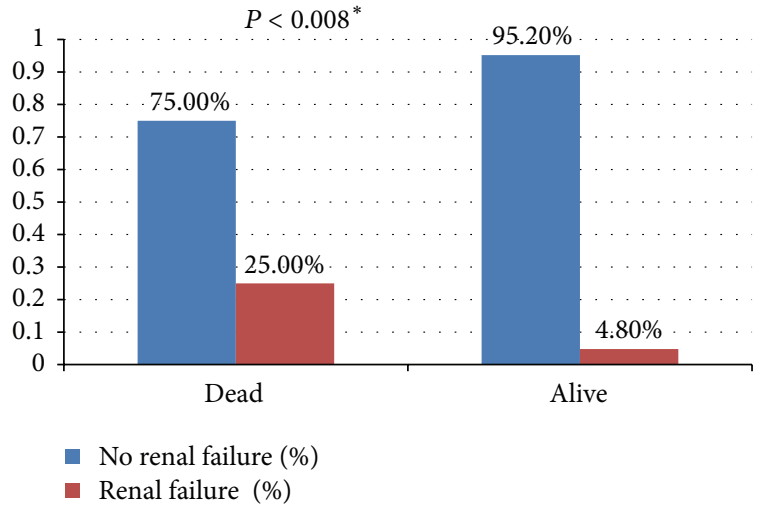

FIGURE 3: Correlation of incidence of renal failure with in-hospital mortality of the study group.

the ROC analysis with sensitivity of $70 \%$, specificity $69 \%$, and $95 \%$ confidence interval (CI) of $67-89 \%$. The cutoff value of creatinine, 1st day was around $\geq 1 \mathrm{mg} / \mathrm{dL}$ with sensitivity of $80 \%$, specificity of $79 \%$, and $95 \%$ CI of $81-100 \%$ (Figure $4(a)$ ). As shown in Figure 5(a) creatinine $(\mathrm{mg} / \mathrm{dL})$ and serum CK IU/L are highly correlated. On linear regression of their natural logs, Ln serum CK $=772.7+880.76$, serum CK was significantly related to creatinine, with $\beta=0.36$ and $R^{2}=0.128(P<0.008)$.

The cutoff value of serum CK on the 3rd day was around $\geq 1146 \mathrm{IU} / \mathrm{L}$ with sensitivity of $55.5 \%$, specificity of $55.5 \%$, and $95 \%$ CI of $54-87 \%$ (Figure $4(\mathrm{~b})$ ). The cutoff value of creatinine 1st day was around $\geq 0.9 \mathrm{mg} / \mathrm{dL}$ with sensitivity of $90 \%$, specificity of $72 \%$ and $95 \%$ CI of $79-100 \%$ (Figure 5(b)). As shown in Figure 5, creatinine (mg/dL) and serum CK IU/L are highly correlated. On linear regression of their natural logs, Ln serum CK $=1395+814$, serum CK was significantly related to creatinine, with $\beta=0.34$ and $R^{2}=0.115(P<$ $0.000)$.

The cutoff value of serum CK on the 5th day was around $\geq 1754 \mathrm{IU} / \mathrm{L}$ with sensitivity of $75 \%$, specificity of $71 \%$, and $95 \%$ CI of $53-92 \%$. The cutoff value of creatinine 5 th day was around $\geq 0.9 \mathrm{mg} / \mathrm{dL}$ with sensitivity of $86 \%$, specificity of $85 \%$ and $95 \%$ CI of $79-100 \%$ (Figure $4(\mathrm{c})$ ). As shown in Figure 5(c), Creatinine $(\mathrm{mg} / \mathrm{dL}$ ) and serum CK IU/L are highly correlated. On linear regression of their natural logs, Ln serum CK $=902+688$, serum CK was significantly related to creatinine, with $\beta=0.41$ and $R^{2}=0.167(P<0.004)$.

\section{Discussion}

There are only a limited number of reports on incidence of patients developing renal failure in all types of injured patients who were admitted in a tertiary care trauma centre under red area. Our study comprised 107 patients of average age $28(30-83)$ years who were admitted due to various types of trauma, out of which head injured patients were maximum. Patient groups were divided on the basis of type of organ failure and compared. Incidence of renal failure was 10 out

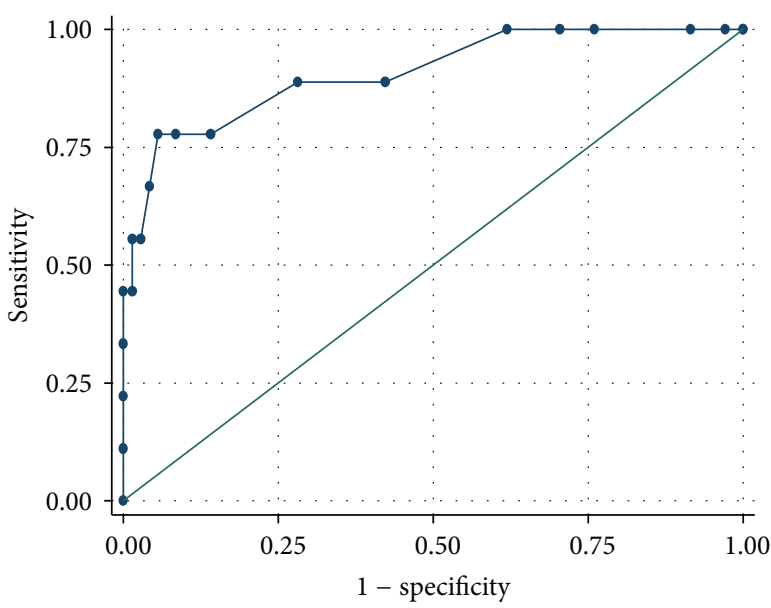

Area under ROC curve $=0.9077$

(a)

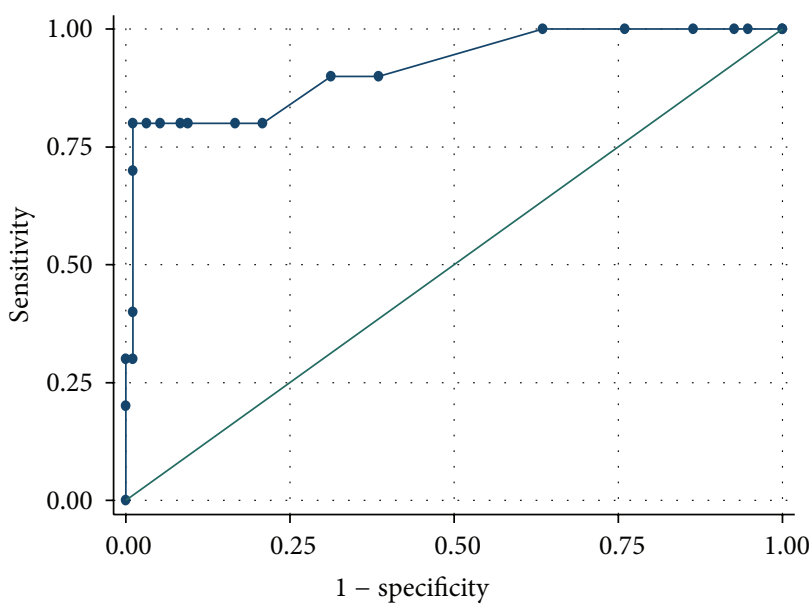

Area under ROC curve $=0.9177$

(b)

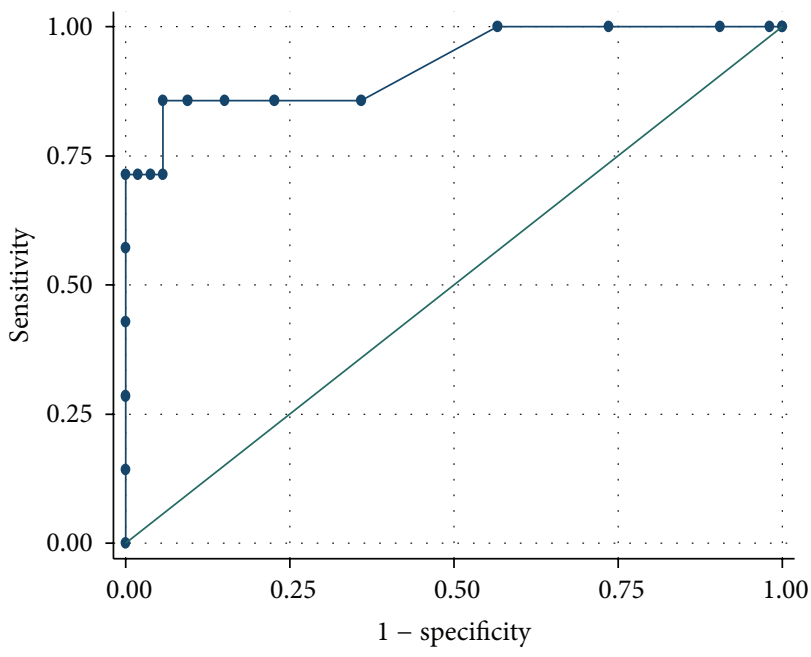

Area under ROC curve $=0.9259$

(c)

FIGURE 4: ROC curve analysis for serum creatine on admission, day 3 and day 5 of followup in traumatic patients who developed renal failure. 


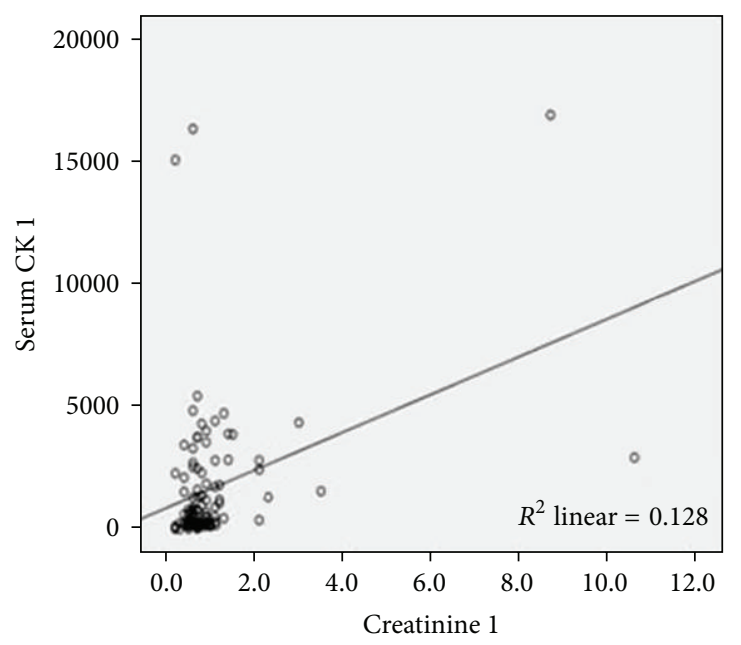

(a)

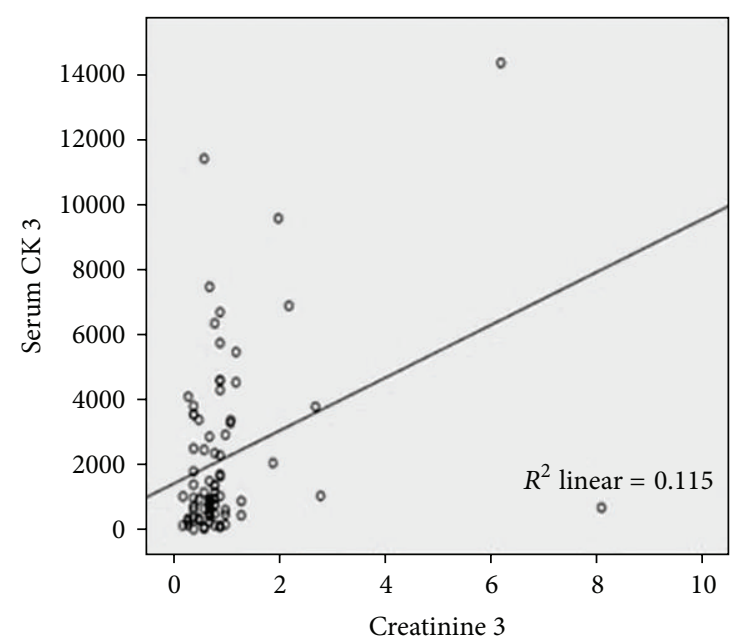

(b)

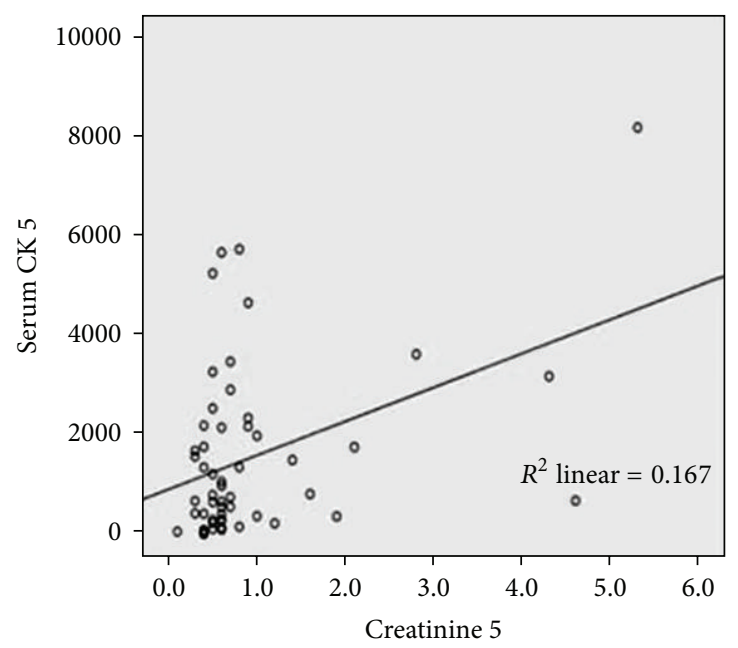

(c)

FIGURE 5: Correlation of creatine (mg/dL) and serum CK (IU/L) on admission, day 3 and day 5 of followup in traumatic patients who developed renal failure.

of $107(9.3 \%)$ and mortality in this group was 60\%. In our study, posttraumatic renal failure (PTRF) was defined as the occurrence of serum creatinine $\geq 2 \mathrm{mg} / \mathrm{dL}$ after admission for trauma. Similar to our study, Gomes et al. also reported that incidence of renal failure varies from less than $0.1 \%$ to $18 \%$, with an associated mortality ranging from 7 to $83 \%$.

Acute Dialysis Quality Initiative Group, a panel of international experts in nephrology and critical care medicine, developed and published a set of consensus criteria for a uniform definition and classification of AKI. These criteria, which make up the acronym "RIFLE," classify renal dysfunction according to the degree of impairment present: there are three grades of severity-risk (R), injury (I), and failure (F) - and two outcome classes - sustained loss (L) of kidney function and end-stage kidney disease (E) [10].

Although the cause of posttraumatic renal failure is likely multifactorial, renal ischemia appears to be a contributing factor in at least half of patients [11]. Rhabdomyolysis generally occurs after a trauma, but it can also be caused by genetic conditions, metabolic disorders, exercise, toxins, infections, and drugs, and so forth $[12,13]$. It has become an important issue to prevent the victims of devastating trauma which leads to renal failure. As reported by Thomas and Ibels, ARF due to rhabdomyolysis accounts for up to $9 \%$ of all cases of ARF [14].

We also calculated the cutoff values of serum CK for development of renal failure on the 1st, 3rd, and 5th days by ROC analysis which came out to be $\geq 1320 \mathrm{IU} / \mathrm{L}$, $\geq 1146 \mathrm{IU} / \mathrm{L}$, and $\geq 1754 \mathrm{IU} / \mathrm{L}$, respectively, and serum creatinine was also found to be highly correlated with CK. The sensitivity on the 1st, 3rd, and 5th day was $70 \%$, $55.5 \%$, and $75 \%$, respectively. The specificity of serum CK on the 1st, 3rd, and 5 th days was $69 \%, 55.5 \%$, and $71 \%$, respectively. Hence, trauma patients with serum $\mathrm{CK}$ values above these cutoffs are more prone to develop renal failure. 
Erek et al. [15] studied 639 Marmara earthquake patients with acute renal failure due to crush injuries and reported mean CK value to be 23443 IU/L. In our study, on admission mean CK value was $620 \mathrm{IU} / \mathrm{L}$. Incidence of sepsis in their study was $18.9 \%$ as compared to $3.7 \%$ in the present study.

Oda et al. studied patients having crush syndrome following an earthquake, finding that the risk of renal failure was higher in the patients with serum $\mathrm{CK}$ activities greater than $75000 \mathrm{U} / \mathrm{L}$ [1]. In another study done by Smith and Hardcastle on 334 trauma patients, serum CK of $>8500 \mathrm{U} / \mathrm{L}$ predicted renal failure [16].

In our study on the 1st day, 57 patients were found positive for urine myoglobin by dipstick test, out of which $10 \%$ developed renal failure. This association was not found to be statistically significant. A similar study was done by Loun et al. who concluded that the amount of myoglobin recovered after filtration varied from $<1$ to $38 \%$, and using this method of ultrafiltration/dipstick may result in the misdiagnosis of patients with high myoglobin concentration who are precarious to renal failure when urine myoglobin the $<60,000 \mu \mathrm{g} / \mathrm{L}$ [17].

Hence, this study revealed that a rapid urine test for myoglobin and serum $\mathrm{CK}$ can provide rapid and reliable examination for early diagnosis of renal failure in those with any type of minor, major, or severe trauma/road traffic accident (RTA). However, in some of the studies done on patients with rhabdomyolysis, it was concluded that measuring myoglobin and CK levels was not informative in predicting the risk of developing renal failure $[18,19]$. Rapid and reliable diagnostic tools may provide invaluable benefit in subsequent management of posttraumatic patients in preventing renal failure and thereby improving their prognosis. However, further studies are required to assess its efficacy in a prospective setup. Limitation of our study is that most of our patients had their urine checked via a Foley catheter collection which may prevent contamination with blood or other tissue fluid and RIFLE criteria of grading was not done.

\section{Conclusion}

Patients who suffer from severe traumatic injuries are prone to develop renal failure. Hence, screening via biomarkers such as urine myoglobin and serum $\mathrm{CK}$ is required. Incidence of renal failure in our study was 9.3\%. Although in our study urine myoglobin correlation with renal failure was not proved as statistically significant, further studies are required to prove its role. The cutoff values of serum $\mathrm{CK}$ on the 1 st, $3 \mathrm{rd}$, and 5 th days were $\geq 1320 \mathrm{IU} / \mathrm{L}, \geq 1146 \mathrm{IU} / \mathrm{L}$, and $\geq 1754$ IU/L, respectively. Hence, evaluating for serum CK in posttraumatic patients can help in early detection of renal failure and improvement in prognosis.

\section{Disclosure}

The paper was presented in Trauma Conference 2012 (international) and won the best poster award.

\section{Conflict of Interests}

The authors declare that they have no conflict of interests.

\section{Acknowledgment}

The authors would like to sincerely thank the chief of trauma centre, Dr. M. C. Misra, for his constant support.

\section{References}

[1] J. Oda, H. Tanaka, T. Yoshioka et al., "Analysis of 372 patients with crush syndrome caused by the Hanshin-Awaji earthquake," Journal of Trauma-Injury, Infection and Critical Care, vol. 42, no. 3, pp. 470-476, 1997.

[2] M. M. Ward, "Factors predictive of acute renal failure in rhabdomyolysis," Archives of Internal Medicine, vol. 148, no. 7, pp. 1553-1557, 1988.

[3] D. Roth, F. J. Alarcon, J. A. Fernandez, R. A. Preston, and J. J. Bourgoignie, "Acute rhabdomyolysis associated with cocaine intoxication," The New England Journal of Medicine, vol. 319, no. 11, pp. 673-677, 1988.

[4] E. K. Rice, N. M. Isbel, G. J. Becker, R. C. Atkins, and L. P. McMahon, "Heroin overdose and myoglobinuric acute renal failure," Clinical Nephrology, vol. 54, no. 6, pp. 449-454, 2000.

[5] T. B. Briggs and R. R. Smith, "Exertional rhabdomyolysis associated with decerebrate posturing," Neurosurgery, vol. 19, no. 2, pp. 297-299, 1986.

[6] J. P. Knochel, "Rhabdomyolysis and myoglobinuria," Annual Review of Medicine, vol. 33, pp. 435-443, 1982.

[7] R. W. Hamilton, M. B. Hopkins III, and Z. K. Shihabi, "Myoglobinuria, hemoglobinuria, and acute renal failure," Clinical Chemistry, vol. 35, no. 8, pp. 1713-1720, 1989.

[8] E. A. J. Hoste, G. Clermont, A. Kersten et al., "RIFLE criteria for acute kidney injury are associated with hospital mortality in critically ill patients: a cohort analysis," Critical Care, vol. 10, no. 3, article R73, 2006.

[9] A. E. Baue, "MOF, MODS, and SIRS: what is in a name or an acronym?" Shock, vol. 26, no. 5, pp. 438-449, 2006.

[10] E. Gomes, R. Antunes, C. Dias, R. Araújo, and A. Costa-Pereira, "Acute kidney injury in severe trauma assessed by RIFLE criteria: a common feature without implications on mortality?" Scandinavian Journal of Trauma, Resuscitation and Emergency Medicine, vol. 18, article 1, 2010.

[11] H. H. Rasmussen and L. S. Ibels, "Acute renal failure. Multivariate analysis of causes and risk factors," The American Journal of Medicine, vol. 73, no. 2, pp. 211-218, 1982.

[12] T. Iitsuka, A. Koyama, M. Kobayashi et al., "Acute renal failure due to rhabdomyolysis-clinical investigation on our 6 cases," Japanese Journal of Nephrology, vol. 34, no. 3, pp. 317-324, 1992.

[13] V. E. Schulze Jr., "Rhabdomyolysis as a cause of acute renal failure," Postgraduate Medicine, vol. 72, no. 6, pp. 145-157, 1982.

[14] M. A. Thomas and L. S. Ibels, "Rhabdomyolysis and acute renal failure," Australian and New Zealand Journal of Medicine, vol. 15, no. 5, pp. 623-628, 1985.

[15] E. Erek, M. S. Sever, K. Serdengeçti et al., "An overview of morbidity and mortality in patients with acute renal failure due to crush syndrome: the Marmara earthquake experience," Nephrology Dialysis Transplantation, vol. 17, no. 1, pp. 33-40, 2002. 
[16] W. A. Smith and T. C. Hardcastle, "A crushing experience: the spectrum and outcome of soft tissue injury and myonephropathic syndrome at an Urban South African University Hospital," African Journal of Emergency Medicine, vol. 1, no. 1, pp. 17-24, 2011.

[17] B. Loun, K. R. Copeland, and F. A. Sedor, "Ultrafiltration discrepancies in recovery of myoglobin from urine," Clinical Chemistry, vol. 42, no. 6, pp. 965-969, 1996.

[18] A. H. B. Wu, I. Laios, S. Green et al., "Immunoassays for serum and urine myoglobin: myoglobin clearance assessed as a risk factor for acute renal failure," Clinical Chemistry, vol. 40, no. 5, pp. 796-802, 1994.

[19] D. A. Feinfeld, J. T. Cheng, T. D. Beysolow, and A. M. Briscoe, "A prospective study of urine and serum myoglobin levels in patients with acute rhabdomyolysis," Clinical Nephrology, vol. 38, no. 4, pp. 193-195, 1992. 


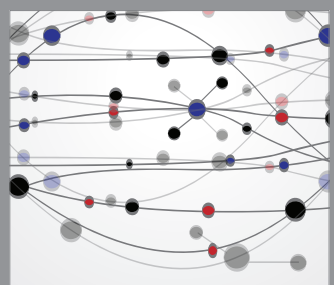

The Scientific World Journal
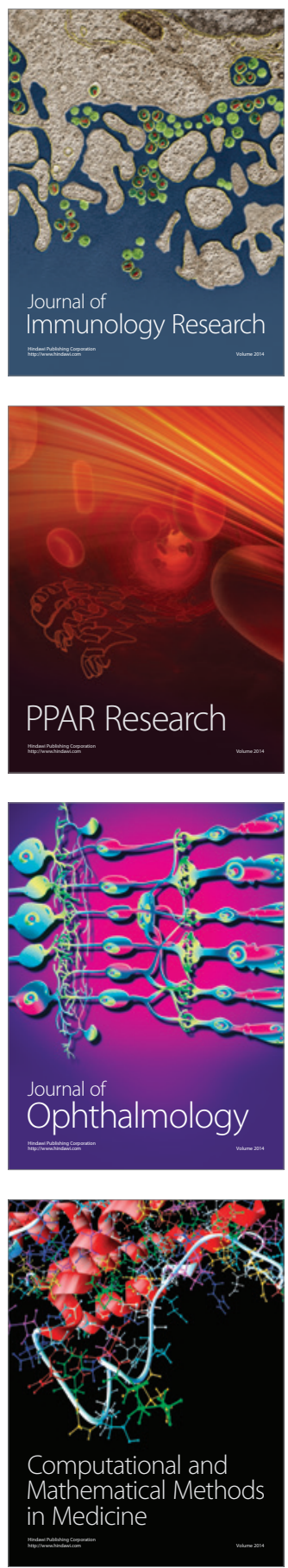

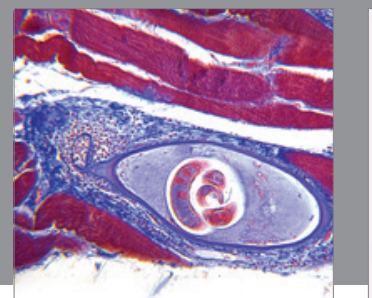

Gastroenterology

Research and Practice
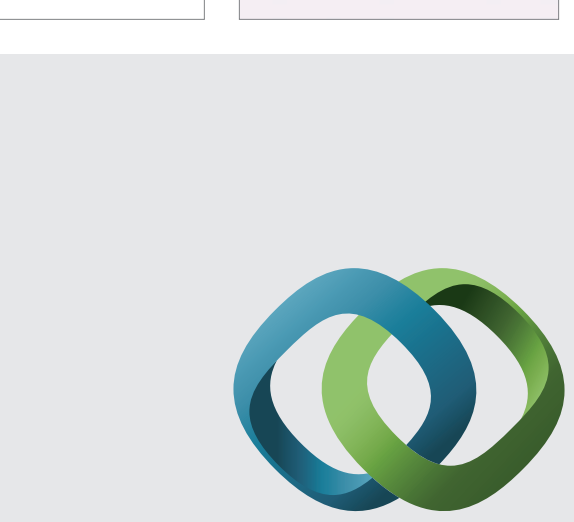

\section{Hindawi}

Submit your manuscripts at

http://www.hindawi.com
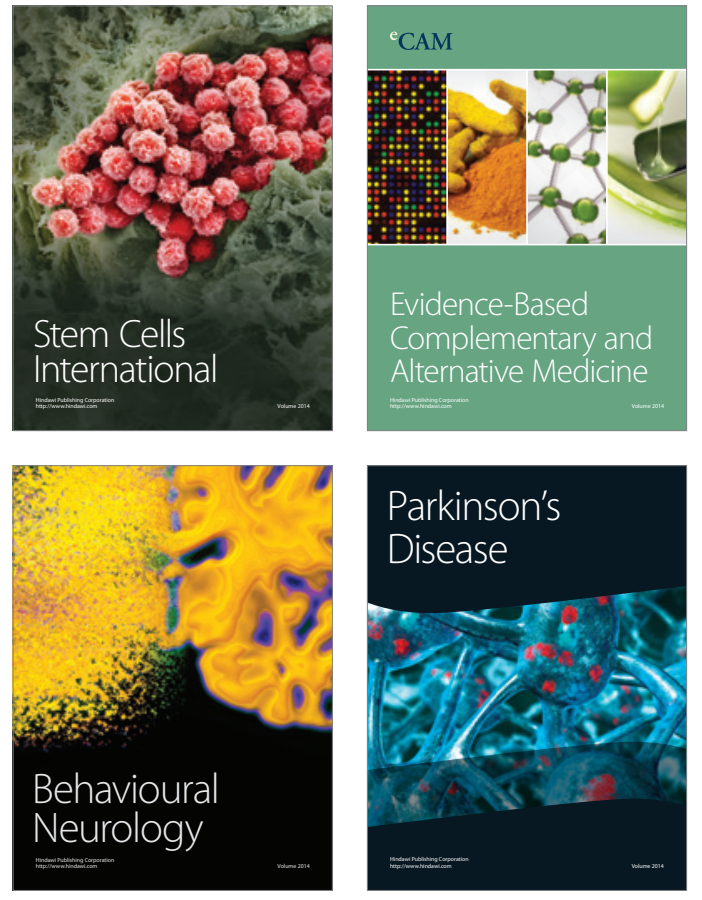
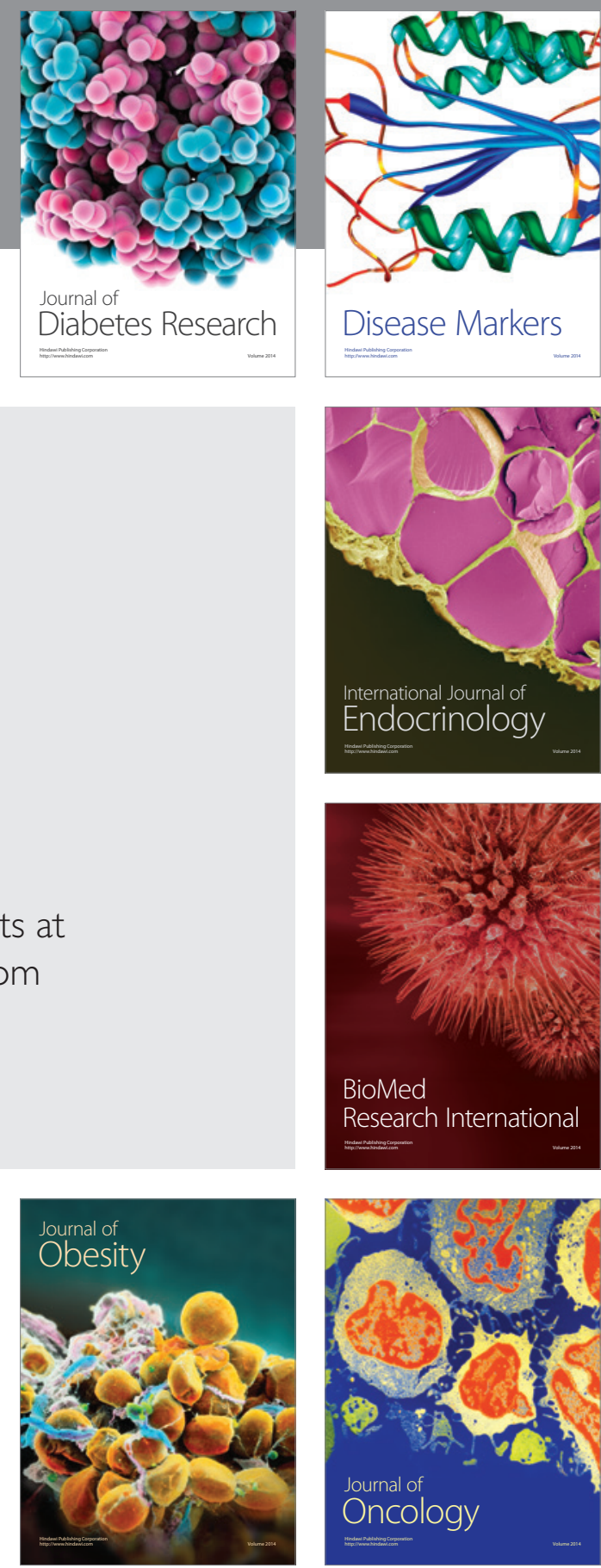

Disease Markers
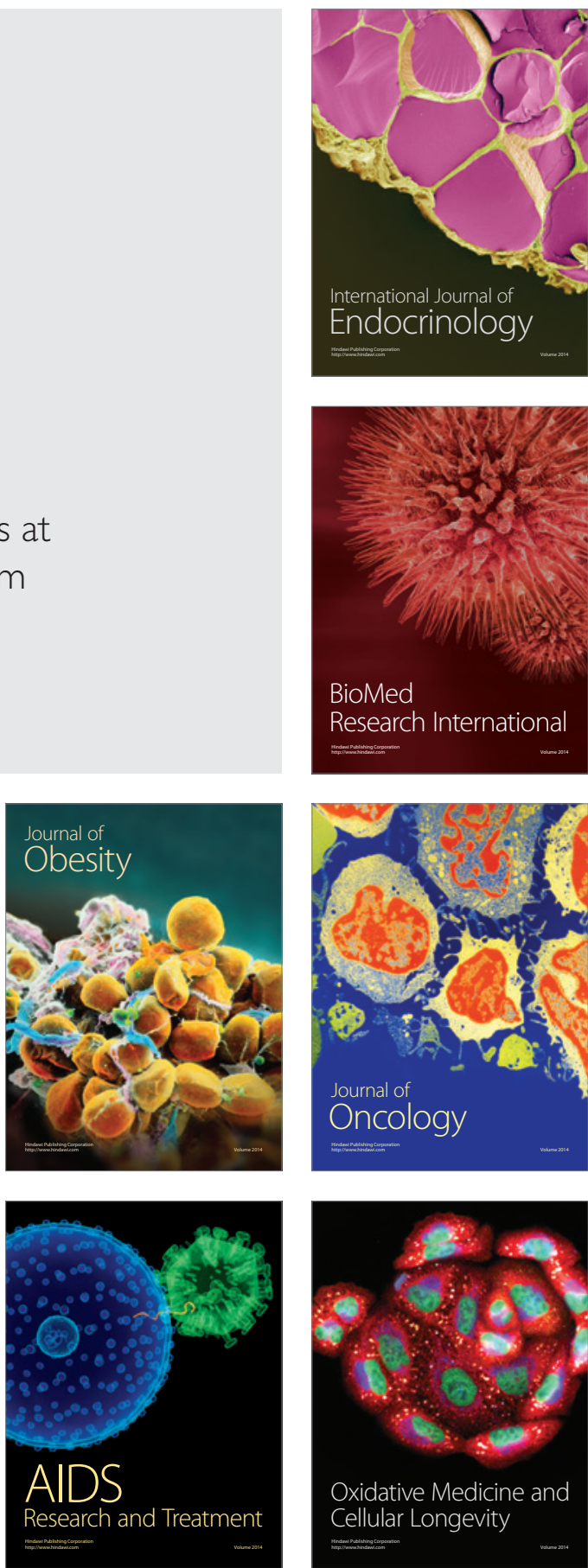